Review article

\title{
An overview on the organic pollution around the Qinghai-Tibet plateau: The thought-provoking situation
}

\author{
Jun $\mathrm{Wu}^{\mathrm{a}}$, Jian Lu ${ }^{\mathrm{b}, *}$, Yongming Luo ${ }^{\mathrm{b}}$, Dongping Duan ${ }^{\mathrm{a}}$, Zhenhua Zhang ${ }^{\mathrm{c}}$, Xiaohu Wen ${ }^{\mathrm{d}}$, Xiuyun Min ${ }^{\mathrm{a}}$, \\ Xiaoying Guo ${ }^{a}$, Brian J. Boman ${ }^{\mathrm{e}}$ \\ a Qinghai Institute of Salt Lakes, Chinese Academy of Sciences, Xining, Qinghai 810008, People's Republic of China

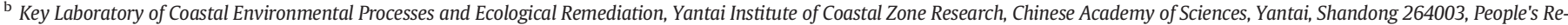 \\ public of China \\ ' School of Resources and Environmental Engineering, Ludong University, Yantai, Shandong 264025, People's Republic of China \\ d Northwest Institute of Eco-Environment and Resources, Chinese Academy of Sciences, Lanzhou, Gansu 730000, People's Republic of China \\ e Indian River Research and Education Center, University of Florida, Fort Pierce, FL 34945-3138, USA
}

\section{A R T I C L E I N F O}

\section{Article history:}

Received 18 July 2016

Received in revised form 23 September 2016

Accepted 23 September 2016

Available online 29 September 2016

\section{Keywords:}

The Qinghai-Tibet plateau

Organic pollutants

Risk assessment

Carcinogenic risk

Non-carcinogenic risk

\begin{abstract}
A B S T R A C T
The Qinghai-Tibet Plateau plays an important role in the ecological safety and human health of the surroundings due to its unique geographical position and function. Therefore, it is necessary to study the pollution status and potential risk in this area. This study summarizes the distribution of different organic pollutants in biota and environmental media of the Qinghai-Tibet Plateau. Moreover, it also pays attention to the potential health risks of these organic pollutants. Organochlorine pesticides (OCPs), polycyclic aromatic hydrocarbons (PAHs), polychlorinated biphenyls (PCBs), and polybrominated diphenyl ethers (PBDEs) were the most frequently detected in different matrices. In general, the carcinogenic risks of organic pollutants were ranked in the verylow to moderate range for both children and adults. The carcinogenic risks of organic pollutants in fish, food, and water for children were 1-2 times higher than those for adults, while risks of organic pollutants in soil/sediment and in air for children were generally 10.6-16.5 and 2.6-2.8 times higher than those for adults, respectively. The maximal hazard quotient for non-carcinogenic risk was 0.95 (potential risk for children posed by organic pollutants in yak milk of Ruoergai), almost reaching an unacceptable level. Therefore, the potential health risks could not be neglected, especially for children who were more likely to be affected by the pollutants.
\end{abstract}

(c) 2016 Elsevier Ltd. All rights reserved.

\section{Contents}

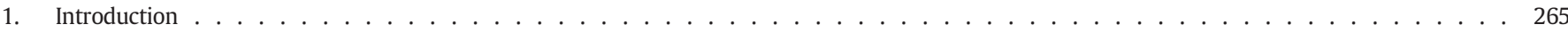

2. Methods and materials . . . . . . . . . . . . . . . . . . . . . . . . . . . . . . 265

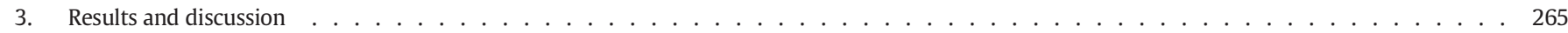

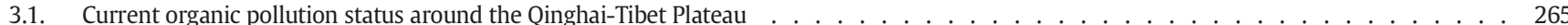

3.1.1. Distribution of OCPs around the Qinghai-Tibet Plateau . . . . . . . . . . . . . . . . . . . . . . . . . . . . 265

3.1.2. PCBs, PBDEs, and PCDD/Fs distribution in the Qinghai-Tibet Plateau . . . . . . . . . . . . . . . . . . . . . . . . . . . 266

3.1.3. PAHs distribution in the Qinghai-Tibet Plateau . . . . . . . . . . . . . . . . . . . . . . . . . . . . . . . . . . . . 268

3.1.4. Other organic pollutants around the Qinghai-Tibet Plateau . . . . . . . . . . . . . . . . . . . . . . . . . . . 270

3.2. Potential risks of the organic pollutants around the Qinghai-Tibet Plateau $\ldots \ldots \ldots$

3.2.1. Risk assessment on fish, food, and water in the Qinghai-Tibet Plateau . . . . . . . . . . . . . . . . . . . . . . . . 270

3.2.2. Risk assessment on soil/sediment in the Qinghai-Tibet Plateau . . . . . . . . . . . . . . . . . . . . . . . . . . . . . . 270

3.2.3. Risk assessment on air in the Qinghai-Tibet Plateau . . . . . . . . . . . . . . . . . . . . . . . . . . . . . . 271

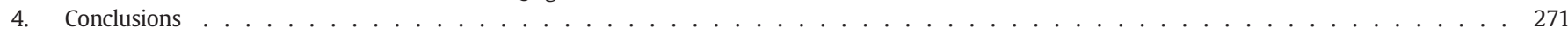

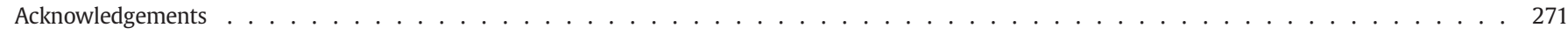

Appendix A. Supplementary data . . . . . . . . . . . . . . . . . . . . . . . . . . . . . . . . 271

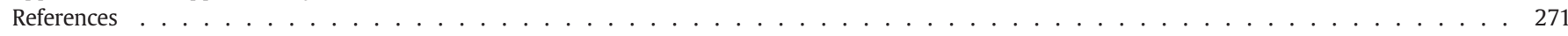

* Corresponding author.

E-mail address: jlu@yic.ac.cn (J. Lu). 


\section{Introduction}

Known as the highest geographical unit in the world, the QinghaiTibet Plateau has attracted increasing attention due to its unique and critical ecological functions. Being the third polar region and roof of the world, the Qinghai-Tibet Plateau is a vast region with area of approximately $3.0 \times 10^{6} \mathrm{~km}^{2}$ (about $2.5 \times 10^{6} \mathrm{~km}^{2}$ in China). Several important rivers including the Yangtze River, the Yellow River, Lancang River, etc. originate in this area that has an average elevation of over $4000 \mathrm{~m}$. Since pollutants originating/being introduced in the QinghaiTibet Plateau have the potential to move thousands of km downstream in these rivers, it is very important to study the pollution status in this area.

Organic contaminants in alpine ecosystems have been recently received more attention due to their potential impact on humans who live within alpine regions or depend on resources such as water originating from high-elevation regions and ecosystems themselves (Daly and Wania, 2005). Chlorinated organic compounds, an important group of organic contaminants, have been widely applied in industry and agriculture. They generally include DDT (dichloro-diphenyltrichloroethane), hexachlorobenzene (HCB), lindane $(\gamma-\mathrm{HCH}$ or gamma-hexachlorocyclohexane), polychlorinated biphenyls (PCBs), polychlorinated dibenzo-para-dioxins (PCDDs), polychlorinated dibenzofurans (PCDFs), and so on. As main parts of organochlorine pesticides (OCPs), DDT, HCB, and HCH have been extensively studied due to their persistence and toxicity (Mrema et al., 2013).

Although PCBs have been banned by many countries and will be eventually eliminated by 2025 (Borja et al., 2005), they are attracting attention due to their environmental persistence and potential threat to human health (USEPA, 1996). In recent decades, flame retardants have been widely added to various consumer products due to their excellent characteristics. However, they have also aroused concerns since these products have increasingly been observed in humans and biota (Meironyté et al., 1999; Dietz et al., 2013). Among them, polybrominated diphenyl ethers (PBDEs) have been extensively studied due to their potential toxicity and environmental persistence (Ni et al., 2013).

Polycyclic aromatic hydrocarbons (PAHs) are a group of over 100 individual compounds containing two or more fused aromatic rings (Barro et al., 2009). PAHs are mainly produced from incomplete combustion/pyrolysis of organic matter, existing in the environment through natural and anthropogenic activities (Purcaro et al., 2013). PAHs have received increasing attentions due to their proven or potential genotoxicity and carcinogenicity (Capone and Bauer, 1992; Purcaro et al., 2013) and their long-distance transportation characteristics (Ravindra et al., 2008; Pandey et al., 2011).

The Qinghai-Tibet Plateau is often regarded as the clean region in China due to its high elevation, small population, broad virgin land, and minimal disturbance by human activities (Wang et al., 2010a; Yang et al., 2013). However, observations in recent years have provided surprising facts (Wang et al., 2007a; Yang et al., 2007; Li et al., 2014). This paper summarizes the concentrations of different organic pollutants including OCPs, PCBs, PBDEs, PCDD/Fs, PAHs, and other organic contaminants in fish, plants, food, soil, water, and air. It also focuses on evaluating the potential health risks of these pollutants in the Qinghai-Tibet Plateau. The final objective of this study is to provide comprehensive information and basis for the environmental protection of this unique area.

\section{Methods and materials}

A review of published articles that included data on organic pollution in the Qinghai-Tibet Plateau was conducted. The data gleaned from these studies are summarized in Tables S1-S4 and locations of the collection sites are shown in Fig. S1.
The potential risks posed by the organic pollutants found in these studies include both carcinogenic risks and non-carcinogenic risks, expressed as the cancer risk $(C R)$ and hazard quotient $(H Q)$, respectively. The equations and parameters for calculating $C R$ and $H Q$ are described by USEPA (1994), Rovira et al. (2010), Pan et al. (2014), Sultana et al. (2014), Liu et al. (2015), USDA (2015), Gerber et al. (2016), and USEPA (2016). Detailed information on the procedures is shown in the Supporting Information section.

\section{Results and discussion}

\subsection{Current organic pollution status around the Qinghai-Tibet Plateau}

\subsubsection{Distribution of OCPs around the Qinghai-Tibet Plateau}

Surprisingly, OCPs were frequently detected in the biota, food, and environmental media of the Qinghai-Tibet Plateau. DDTs, HCHs, and HCB were all detected in fish of this area. DDTs were the dominant pollutant, followed by HCHs and HCB. Yang et al. (2007) analyzed HCHs, DDTs, and HCB in fish from Nam Co Lak, Yamdro Lake, and Lhasa River (Table S1). They found pesticides were easily bioaccumulated in gills. Later, Yang et al. (2010) measured the concentrations of OCPs in fish samples collected from 8 lakes in the Qinghai-Tibet Plateau (Table S1). They speculated that the summer Indian monsoon and winter western jet-stream significantly affect the fate and transport of pollutants in this plateau.

Accordingly, distribution of OCPs in plants (including agricultural crops) showed the same trend of that in fish. DDTs were still the dominant pollutant. Interestingly, $\mathrm{HCHs}$ served as the main pollutants in yak muscle, liver, and milk. Wang et al. (2006) investigated OCPs in spruce needles growing in the Zhangmu-Nyalam region (Table S1). They speculated that technical HCHs might be used in this region because the ratio of $\alpha-\mathrm{HCH} / \gamma-\mathrm{HCH}$ was similar to that of technical HCHs. Moreover, the high ratios of o- $\mathrm{p}^{\prime}-\mathrm{DDT} / \mathrm{p}-\mathrm{p}^{\prime}$-DDT and no detected $\mathrm{p}-\mathrm{p}^{\prime}$-DDE suggested that $0-\mathrm{p}^{\prime}$-DDT and/or $\mathrm{p}-\mathrm{p}^{\prime}$-DDT might come from a new source. Wang et al. (2007a) reported that DDT components were the dominant pollutants among OCPs in the grass from Mt. Everest (Mt. Qomolangma). Concentrations of $\mathrm{HCH}$ and DDT in grass were the same or slightly higher than those in moss collected from Mt. Everest 15 years ago. Wang et al. (2007a) also speculated that OCPs in the Qinghai-Tibet Plateau possibly come from nearby regions (especially India) according to the isomer ratios $\left(\alpha / \gamma-\mathrm{HCH}\right.$ and $\left.\mathrm{p}-\mathrm{p}^{\prime}-\mathrm{DDE} / \mathrm{p}-\mathrm{p}^{\prime}-\mathrm{DDT}\right)$. Yang et al. (2013) analyzed samples of soils, lichens, conifer barks, and needles collected from five transects of the southeastern Qinghai-Tibet Plateau to investigate the accumulation patterns of semivolatile organic pollutants in this region (Table S1). The concentrations of OCPs generally increased with rise in elevation of transects 1,3 , and 4 . Zhu et al. (2015) investigated concentrations of OCPs in lichen, moss and soil collected from the southeastern Qinghai-Tibet Plateau. DDTs, endosulfans, $\mathrm{HCHs}$ and HCB were dominant pollutants in all of the samples (Table S1). DDTs and HCHs in the sampling region had fresh inputs according to source analysis. Significant linear relationships were found between the concentrations of 12 OCPs and 14 PCBs in lichens and the elevation at which they were located. Pan et al. (2014) investigated OCPs and PCBs in grass, yak liver, muscle, and milk in the Ruoergai prairie. DDTs and endosulfans were the main contaminants in grass, with the average concentrations of 2.86 and $1.98 \mu \mathrm{g} / \mathrm{kg}$ dry weight (dw). HCHs readily bioaccumulated in yak liver and milk, with average concentrations of $11.4 \mu \mathrm{g} / \mathrm{kg}$ fresh weight and $4.46 \mu \mathrm{g} / \mathrm{kg}$ fat, respectively. Wang et al. (2016) also reported that the average concentrations of DDTs and $\mathrm{HCHs}$ were, respectively, 0.661 and $0.0364 \mu \mathrm{g} / \mathrm{kg}$ dw in Tibetan highland barley and 1.03 and $0.0225 \mu \mathrm{g} / \mathrm{kg} \mathrm{dw}$ in rape. OCPs did not significantly bioaccumulate in crops, especially $\mathrm{HCHs}$.

The distribution of OCPs in soil and water was somewhat site-specific. However, the concentrations of DDTs were generally higher than those of other OCPs. For example, only DDT components were detected in the soil samples from Mt. Everest $(0.385-6.06 \mu \mathrm{g} / \mathrm{kg})$ while HCB and 
HCHs were not detected in the same samples (Wang et al., 2007a). Wang et al. (2007b) studied OCPs in fresh-fallen snow on East Rongbuk Glacier of Mt. Everest at different elevations. DDT components in snow showed elevation cold-trap effects while HCB did not. Xing et al. (2010) reported that the concentrations of HCHs and DDTs in soil ranged from 0.22 to 1.45 and from 0.15 to $6.69 \mu \mathrm{g} / \mathrm{kg}$, respectively. The results confirmed the long-range atmospheric transport of OCPs. Results obtained by Tao et al. (2011) showed that average concentrations of HCHs and DDT components in soil samples from 28 sites of the Qinghai-Tibet Plateau were 0.329 and $0.467 \mu \mathrm{g} / \mathrm{kg}$, respectively. Interestingly, some scientists reported that the HCB concentration in urban soil sample from Xining was very high $(9.79 \mu \mathrm{g} / \mathrm{kg}$ ) (Huang et al., 2014). Wang et al. (2012) investigated the concentrations of DDTs, HCHs, and $\mathrm{HCB}$ in 40 surface soil samples $(0-5 \mathrm{~cm})$ (Table $\mathrm{S} 1)$. They found that soil DDT, HCB, PCB and PBDE concentrations were strongly influenced by soil organic carbon (SOC) content. Whereas the average concentrations of HCHs, DDTs, and HCB in soil samples collected from the southeastern the Qinghai-Tibet Plateau were $0.40,2.85$, and $0.17 \mu \mathrm{g} / \mathrm{kg}$, respectively (Yang et al., 2013). Liu et al. (2013a) speculated that the agricultural fields in the Sichuan Basin might be a major source of the OCPs in soils along the Mianzhu-Aba profile. They found concentrations of DDTs decreased with the increasing elevation. Moreover, they concluded that risks posed by OCPs in water of this area were moderate while heptachlor, aldrin, $\mathrm{HCB}$, and $\mathrm{HCH}$ might pose potential carcinogenic effect if these pollutants exist in drinking water (Liu et al., 2015). Wang et al. (2014a) found that DDTs were highly stable in forest soils after they analyzed OCPs in 7 soil profiles from Mt. Sygera. They also confirmed higher accumulation of OCPs in forest soil of the Qinghai-Tibet Plateau. Zhu et al. (2015) found that DDTs accounted for about 54\% of total 28 OCPs with average concentration of $0.65 \mu \mathrm{g} / \mathrm{kg}$. Wang et al. (2016) investigated concentrations of DDTs and $\mathrm{HCHs}$ in Tibetan agricultural soils with the average values of 1.36 and $0.349 \mu \mathrm{g} / \mathrm{kg}$ dw, respectively.

The distribution of OCPs in sediment was also site-specific. Tao et al. (2014) investigated deposition and regional distribution of HCHs and p, $\mathrm{p}^{\prime}$-DDX (DDT, DDD, and DDE) from a lake sediment core and surface soils in the western and southern Qinghai-Tibet Plateau (Table S1). Cheng et al. (2014) collected sediment cores from 5 critical regions in the Qinghai-Tibet Plateau (Table S1). The DDT and HCH concentrations in sediments collected from Yamzho Yumco Lake, Nam Co Lake, and Star Sea all have increased since the late 1980s. Lake sediment is regarded as an important sink for OCPs. Therefore, increased glacier melt-water resulting from global warming would be expected to increase the potential for recycling organic pollutants such as OCPs in the QinghaiTibet Plateau (Cheng et al., 2014).

Li et al. (2006), Cheng et al. (2007), and Xiao et al. (2010) studied OCPs in air of the Qinghai-Tibet Plateau. Concentrations of HCHs in air were generally higher than that reported for other pollutants, with DDTs and endosulfan also being important components. Maximum $\mathrm{HCHs}$, DDXs, and HCB concentrations occurred in Waliguan, with values of 281,157 , and $71 \mathrm{pg} / \mathrm{m}^{3}$, respectively. Wang et al. (2010a) collected air samples at 16 locations on the Qinghai-Tibet Plateau using passive air samplers to investigate the persistent organic pollutants in the atmosphere (Table S1). The highest concentrations of HCB, PCBs, and PBDEs were found at a site impacted by a forest fire during sampling. Ren et al. (2014) reported higher DDTs levels in air of the southeastern Tibetan Plateau during the monsoon season $\left(20.5-57.4 \mathrm{pg} / \mathrm{m}^{3}\right)$ than those during the non-monsoon season $\left(9.2-27.4 \mathrm{pg} / \mathrm{m}^{3}\right)$. The results showed Mt. Sygera might be a receptor region from the Indian subcontinent. Zhu et al. (2014) investigated concentrations and patterns of 28 OCPs in the air of the Mt. Shergyla. Predominant compounds in the air included endosulfan, $\mathrm{HCB}$, pentachlorobenzene, hexachlorocyclohexanes and dichlorodibenzotrichloroethane and its degradation products (DDTs).

3.1.2. $P C B S$, PBDEs, and PCDD/Fs distribution in the Qinghai-Tibet Plateau

PCB, PBDEs, and PCDD/Fs widely existed in biota, food, and environmental media. Yang et al. $(2010,2011)$ measured the concentrations of
PCBs and PBDEs in fish samples collected from 8 lakes in the QinghaiTibet Plateau (Table S2). The results showed that the temperature, precipitation, longitude, and latitude of the sampling sites significantly affected concentration variation of PBDEs and mercury in fish. The transport and fate of organic pollutants were particularly affected by the Indian monsoon and westerly jet stream.

The concentrations of PCBs and PBDEs were related to the species of plants. Zhu et al. (2015) reported that the average concentrations of PBDEs, PCBs, and HBCDs (hexabromocyclododecane congeners) in lichen and moss were $0.16 / 0.36 / 0.14$ and $0.028 / 0.30 / \mathrm{ND} \mu \mathrm{g} / \mathrm{kg}$, respectively. The concentrations of 13 PBDEs, 18 PCBs and 3 HBCDs were much lower than that of 28 OCPs. Concentrations of PCBs in lichens were significantly related to elevation, while contaminants in mosses did not show clear relationship with elevation. Liu et al. (2014a) measured concentrations of 24 PCBs in soil, moss, and air from nine elevations on the eastern slope of Mt. Gongga (Table S2). They found that mosses were more capable of retaining heavier PCBs. Furthermore, PCBs in mosses did not show significant relationship with elevation. Li et al. (2014) reported that the average concentration of PCDD/Fs in Rouzi grass collected from Zhangmu-Nyalam was $62.0 \mathrm{ng} / \mathrm{kg}$. PCDD/Fs could bioaccumulate in vegetation based on the higher concentrations in grass and lower concentrations in soil.

The concentrations of PCBs and PBDEs in food were relatively high. Wang et al. (2010b) explored the concentrations of PCBs and PBDEs in 32 Tibetan butter samples collected from seven prefectures and 3 comparative samples from Sichuan, Gansu, and Qinghai. Concentrations of 25 PCBs in the Tibetan butters were lower than that from Sichuan province $(2518 \mathrm{ng} / \mathrm{kg})$. The concentrations of 12 PBDEs in the Tibetan butters were far lower than the PCB concentrations (Table S2). Atmospheric deposition was the source of PCBs and PBDEs in the southern Plateau whereas tropical monsoons from South Asian were the main pollution source in the Western Plateau based on back trajectory models. Pan et al. (2014) found that PCBs were not detected in yak muscle and liver, and only low concentrations were reported in yak milk.

PCBs were the dominant pollutant in air around the Qinghai-Tibet Plateau. Cheng et al. (2007) reported concentrations of PBDEs in air of Waliguan, with average value of $8.3 \mathrm{pg} / \mathrm{m}^{3}$. The high concentrations of PBDEs were mainly related to long-distance air mass transport from the adjacent regions such as Russia and Kazakhstan. Xiao et al. (2010) found the concentrations of PCBs in air near Nam Co Lake were low (Table S2), and there was low pollution potential. Ren et al. (2014) reported PCBs concentrations in air of the southeastern Qinghai-Tibet Plateau (Table S2) and speculated that the forests of the southeastern Qinghai-Tibet Plateau might form an important barrier (called a forest filter effect) to obstruct the long-distance transport of organic pollutants. Zhu et al. (2014) investigated the concentrations and patterns of 25 PCBs, 13 PBDEs, and 3 HBCD isomers in the air of the Mt. Shergyla. Most of the target POPs had significantly higher concentrations in summer than in winter. PBDEs and HBCDs showed the lowest background concentrations. Liu et al. (2014a) reported that PCB28 was the dominant congener, whereas the concentrations of heavier congeners were always below $1 \mathrm{pg} / \mathrm{m}^{3}$ in air of the eastern slope of Mt. Gongga. Wang et al. (2014a) reported PCBs in forest soils of Mt. Sygera. They speculated that PCBs could be translocated in the organic layer of forest soil and transported downward to the deeper soils. Li et al. (2014) also investigated the concentrations of PCDD/Fs in soils of Zhangmu-Nyalam. The average content of PCDD/Fs in soils was $24.3 \mathrm{ng} / \mathrm{kg}$,

PCBs were also the dominant pollutant in soil around the QinghaiTibet Plateau while PBDEs and PCDD/Fs had relatively high concentrations. Wang et al. (2009) investigated PCBs and PBDEs trends in surface soil along relative to elevation in the Qinghai-Tibet Plateau (Table S2). They found two opposite relationship between pollutant concentration and elevation. Below $4500 \mathrm{~m}$, the concentration trend was negative and above this elevation, the relationship was positive. Furthermore, the results showed less volatile congeners were enriched more easily than more volatile chemicals at higher elevation regions. Wang et al. 
(2012) reported that the concentrations of 15 PCBs and 9 PBDEs in soils were in the range of 75-1021 and BDL (below detection limit) to $27 \mathrm{ng} /$ $\mathrm{kg} \mathrm{dw}$, respectively. Zheng et al. (2012) investigated PCBs and PBDEs in soil under the condition of air transport (Table S2). Total toxic equivalency (TEQ) of dioxin-like PCBs ranged from 22 to $94 \mathrm{fg}$ TEQ/g. The results suggested that total organic carbon (TOC) played a significant role in accumulation potential of POPs and dominated the soil-air exchange of PCBs. Yuan et al. (2012a, 2012b) investigated the elevation distribution of 42 PBDE congeners in the mountains of the Central Plateau (Table S2). The PBDE concentrations were normalized by SOC and mineral contents and were found to be positively related to the elevation in this area. BDE-3 was the dominant congener, followed by
BDE-2 and BDE-1. Tian et al. (2014) speculated that cold condensation of PCBs would happen above $4500 \mathrm{~m}$ on the Qinghai-Tibet Plateau. Liu et al. (2014a) measured concentrations of PCBs in soil from the eastern slope of the Mt. Gongga (Table S2). SOC was a key determinant explaining $75 \%$ of the variation in concentration along the elevation gradient. Sun et al. (2015) investigated PBDEs in surface-soil samples from an area near the Changwengluozha Glacier. Clay was proved to play an important role in debromination of PBDEs in soils. Yuan et al. (2015a) found the concentrations of 122 PCBs congeners in 44 soil samples ranged from 66.98 to $150.81 \mathrm{ng} / \mathrm{kg}$. Jia et al. (2014) compared the concentrations of PCDDs and PCDFs in 35 soil samples collected from Fildes Peninsula in the Antarctic, Ny-Ålesund in the Arctic, and Zhangmu-
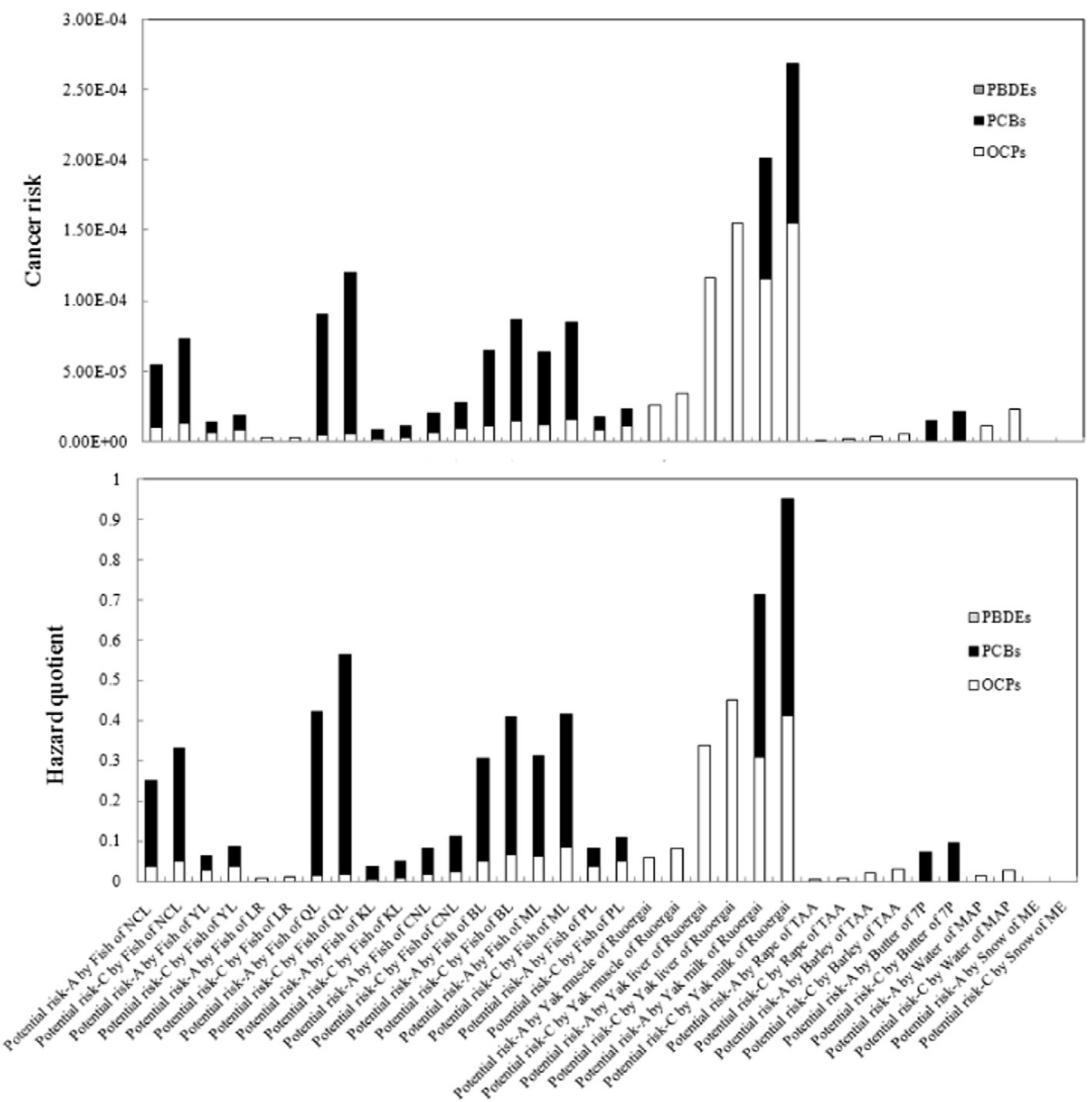

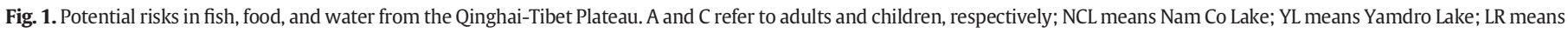

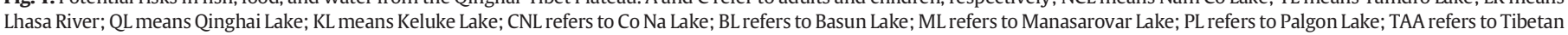
agricultural area; 7P refers to 7 prefectures of the Qinghai-Tibet Plateau; MAP refers to Mianzhu-Aba Profile; ME refers to Mt. Everest. 
Nyalam in the Qinghai-Tibet Plateau. PCDD/Fs concentrations in the soil of Zhangmu-Nyalam were the highest ( $26.22 \mathrm{ng} / \mathrm{kg} \mathrm{dw}$; range $2.43-$ $73.28 \mathrm{ng} / \mathrm{kg} \mathrm{dw}$ ). Zhangmu-Nyalam suffered the highest occurrence of PCDD/Fs due to contributions of both local and regional sources. Tian et al. (2014) reported that concentrations of PCDD/Fs congeners were quadratically related with elevation. Moreover, cold condensation of PCDD/Fs occurred above $4500 \mathrm{~m}$ on the Qinghai-Tibet plateau based on the concentration-elevation curve.

\subsubsection{PAHs distribution in the Qinghai-Tibet Plateau}

Compared with OCPs, PCBs, PBDEs, and PCDD/Fs, PAHs in the plants exhibited the highest concentrations, generally exceeding $10 \mu \mathrm{g} / \mathrm{kg}$ and with a maximum of $638 \mu \mathrm{g} / \mathrm{kg}$. Wang et al. (2006) reported total PAH concentrations in spruce needles growing in the Zhangmu-Nyalam region were below $600 \mu \mathrm{g} / \mathrm{kg}$. PAHs in spruce needles increased with higher elevation. Moreover, high PAHs concentrations along with a positive correlation with elevation implied that PAHs might originate from the nearby sampling sites. Wang et al. (2007c) also investigated total PAH concentrations in grass samples collected from Mt. Everest. Grass types had influence on grass PAH concentrations. Phenanthrene, fluorene, and fluoranthene were the dominant congeners in grass, with the maximum concentrations of 52.8/80.6, 23.2/26.4, and 7.11/ $8.17 \mu \mathrm{g} / \mathrm{kg}$ for Rouzi/Jidou, respectively. They speculated that the combustion for home heating and vehicle emission might be the main
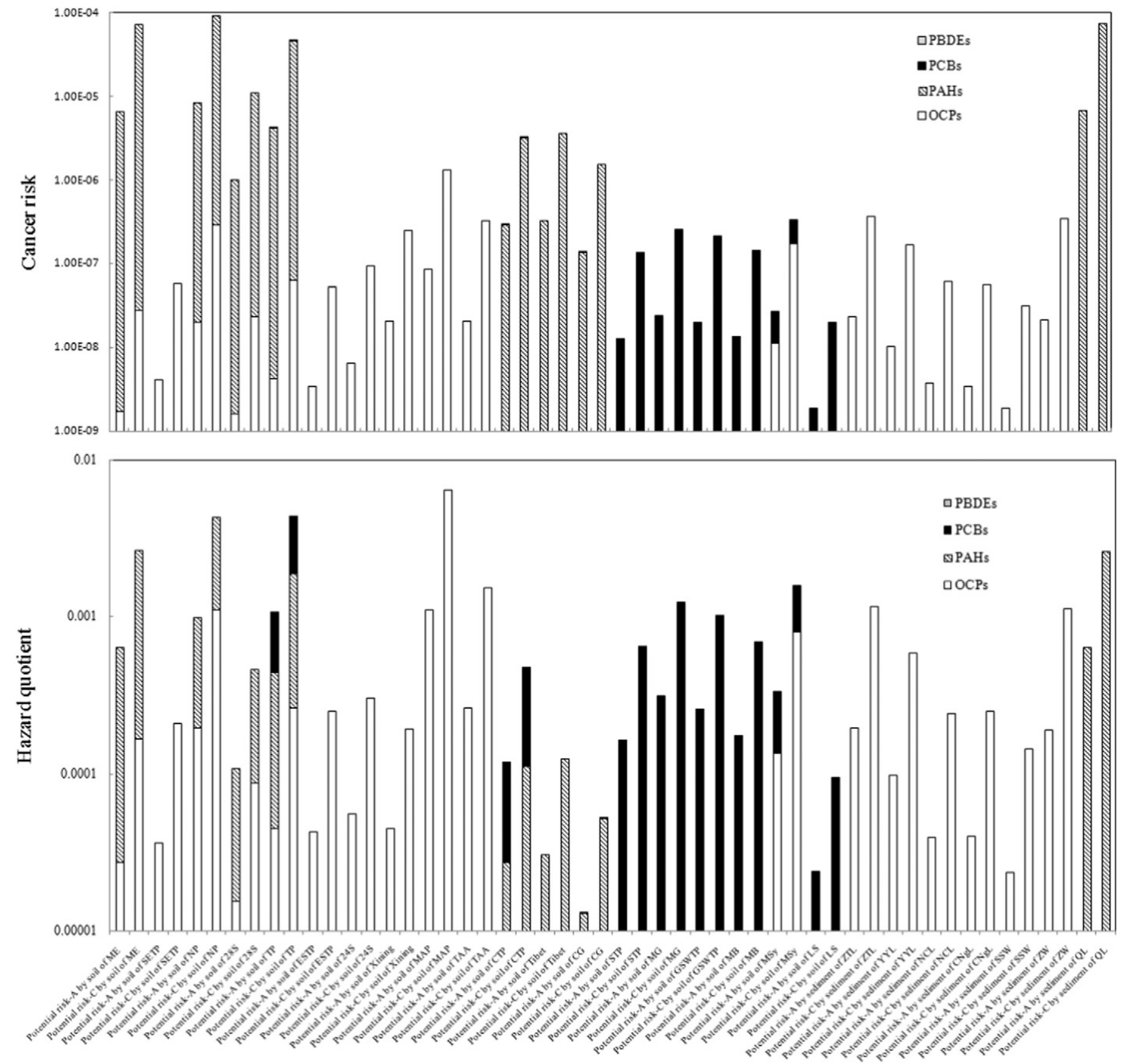

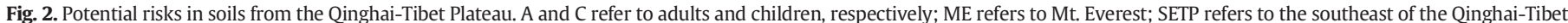

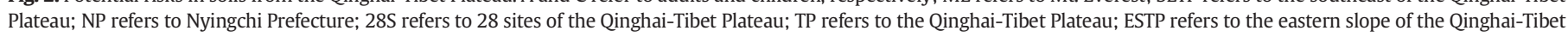

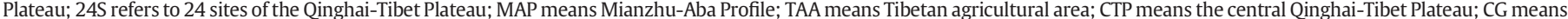

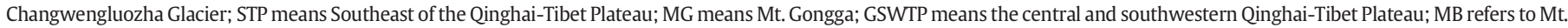

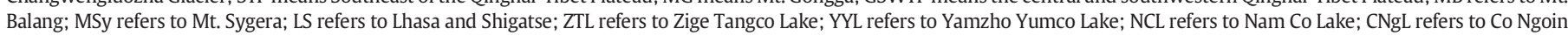
Lake; SSW refers to Star Sea Wetland; ZW refers to Zoige Wetland; QL refers to Qinghai Lake. 
sources of PAHs in this region. Yang et al. (2013) focused on conifer needles, bark, and lichen samples collected from 5 transects along the southeastern plateau (Table S3). Based on the PAH isomer ratios, they deduced that PAHs might be mainly from combustion of different fuels.

There were also high concentrations of PAHs in soil, generally exceeding $50 \mu \mathrm{g} / \mathrm{kg}$ and with a maximum of $770 \mu \mathrm{g} / \mathrm{kg}$. The average concentration of PAHs in soils from 28 sites of the Qinghai-Tibet Plateau was $51.8 \mu \mathrm{g} / \mathrm{kg}$ (Tao et al., 2011). The total concentration of 16 PAHs in soil samples from the Southeastern Plateau were $201 \pm 126 \mu \mathrm{g} / \mathrm{kg}$ (Yang et al., 2013), higher than that reported by Tao et al. (2011). Wang et al. (2014b) reported that the concentrations of PAHs in the surface soils (Table S3). They surmised that the soils were the main sink for heavier PAHs but "secondary source" for lighter PAHs. Elevation played an important role in PAHs distribution in soils. Yuan et al. (2014, 2015b) reported PAHs contents in soils of the Changwengluozha Glacier and the central Qinghai-Tibetan Plateau (Table S3). PAHs in soils of sub-areas might have different sources including combustion of yak/sheep dung and vehicle emissions.
Soils are generally thought to be the main sink for global PAHs cycling. Han et al. (2015) reconstructed the historic deposition of polycyclic aromatic compounds (PACs) in a 150-year-old sediment core from different sub-basins of Lake Qinghai. The concentrations of 28 PAHs, 2/ 3-ring PAHs, and high-molecular-weight PAHs were relatively stable before 1980, and sharply increased thereafter. Concentrations of 4 azaarenes (AZAs) also increased in the upper part of the sediment core in a similar manner to 28 PAHs. He et al. (2015) analyzed 16 priority PAHs in the soils collected from 6 sites of Tibet. Local emission and long-distance transport from Indian might contribute to the higher PAHs in Southeastern Tibet.

Compared with OCPs, PCBs, PBDEs, and PCDD/Fs, PAHs in air exhibited the highest concentrations, generally reaching $\mathrm{ng} / \mathrm{m}^{3}$ levels. Xiao et al. (2010) reported that the total content of 16 PAHs in air of Nam Co Lake varied from 0.080 to $2.23 \mathrm{ng} / \mathrm{m}^{3}$. They found that 3 and 4-ring PAHs were the dominant pollutants in air. Moreover, acenaphthene concentrations significantly increased during the summer. Li et al. (2012) collected $\mathrm{PM}_{2.5}$ in the tents, and TSP in \& out of the tents to

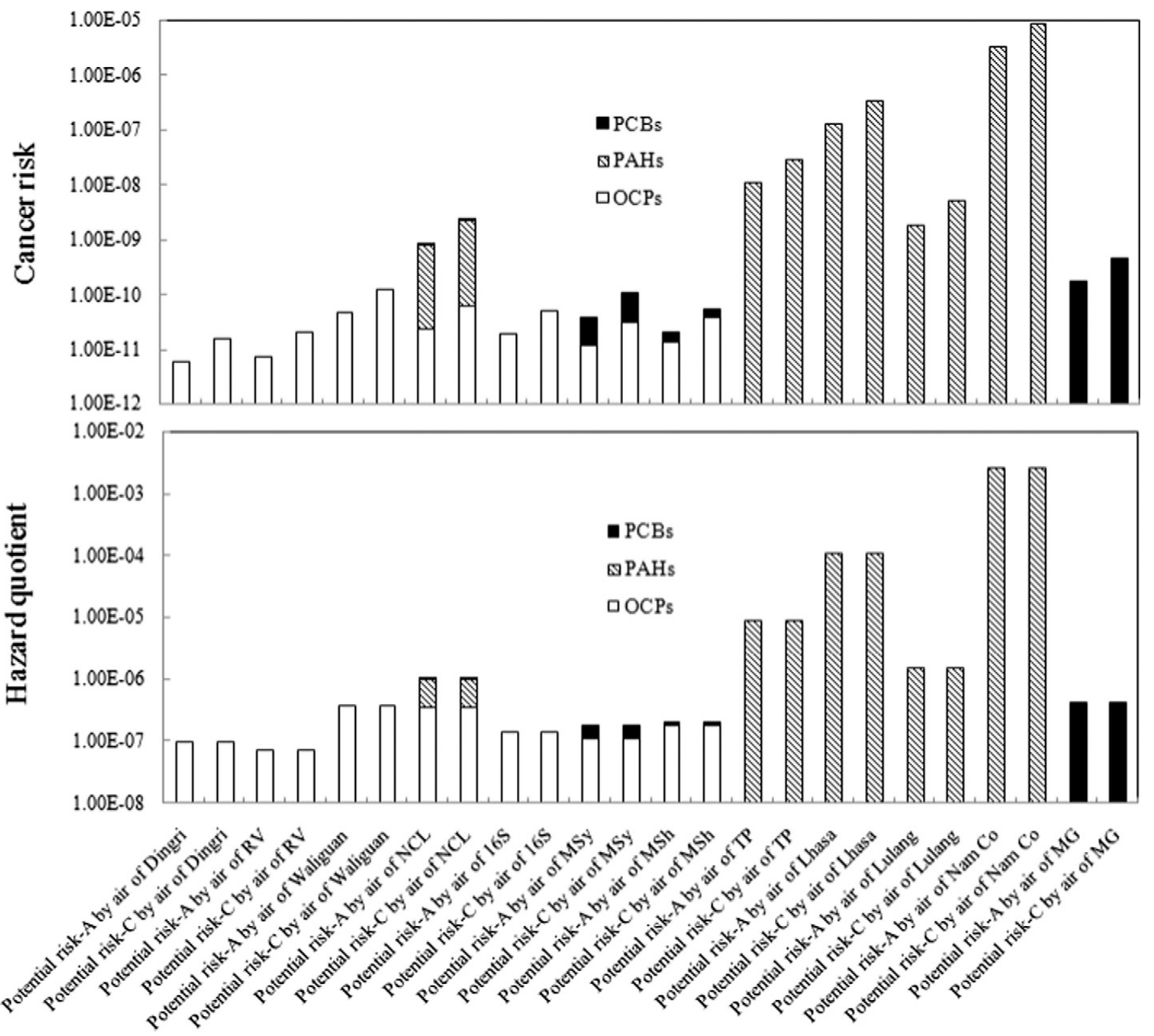

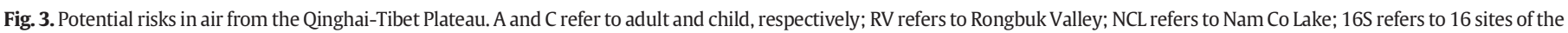
Qinghai-Tibet Plateau; MSy refers to Mt. Sygera; MSh refers to Mt. Shergyla; TP refers to the Qinghai-Tibet Plateau; MG refers to Mt. Gongga. 
explore the distribution of particle-bound PAHs. The average concentration of 13 PAHs in $\mathrm{PM}_{2.5}$ inside tents was $5372.45 \mathrm{ng} / \mathrm{m}^{3}$, much higher than a previous report (Xiao et al., 2010). Li et al. (2012) investigated PAHs bound to fine particulate from nomadic tents in the southern Tibetan Plateau (Table S3). The average concentrations of total PAHs and benzo[a]pyrene (BaP) within tents was a hundred times higher than those of outdoor air on the Plateau. Liu et al. (2013b) analyzed air samples at two suburban sites of Lhasa city (Table S3) and speculated that incomplete wood/cow dung combustion was the main pollution source based on the multiple diagnostic ratios. Chen et al. (2014) investigated the concentrations, seasonal variations, and sources of n-alkanes and PAHs in 62 suspended particle samples collected from Lulang (Table S3). They found that approximately $70 \%$ of PAHs were composed of 5 and 6-ring compounds. The n-alkanes and PAHs showed significant seasonal variation, with higher concentrations in winter and lower concentrations in summer. Wang et al. (2014b, 2015) also investigated PAHs in air and particles (Table S3).

\subsubsection{Other organic pollutants around the Qinghai-Tibet Plateau}

Other organic pollutants such as perfluorinated compounds (PFCs), n-alkanes, etc. were also detected in different environments with nonnegligible concentrations. Shi et al. (2010) reported PFCs in fish muscle collected from lakes in the Qinghai-Tibet Plateau (Table S4). Perfluorooctane sulfonate (PFOS) were detected in $96 \%$ of fish samples. However, concentrations of PFCs were not significantly related with elevation or fish age. Wang et al. (2014c) analyzed perfluoroalkyl acids (PFAAs) in dated snow-cores collected from Mt. Muztagata glacier (accumulation period of 1980-1999) and Mt. Zuoqiupo (accumulation period: 1996-2007). PFAAs in the older Mountain Muztagata core were dominated by PFOS (61.4-346 pg/L) and PFOA (40.8-243 pg/L). The concentrations of PFAAs in the Mountain Zuoqiupo core were lower with PFOA ranging from 37.8 to $183 \mathrm{pg} / \mathrm{L}$ and PFOS was below detection limits. $\mathrm{C}_{4}-\mathrm{C}_{7}$ PFCs, particularly Perfluorobutanoic acid (PFBA), dominated the recent surface snowpack of Lake Namco, showing the highest concentrations of $913-2569 \mathrm{pg} / \mathrm{L}$.

Xie et al. (2010) measured organic compounds in snow and ice samples from the Dasuopu glacier. The concentrations of the extractable organic matter were in the range of 33.8-55.7 $\mu \mathrm{g} / \mathrm{L}$, with a mean value of $45.4 \mu \mathrm{g} / \mathrm{L}$. The concentrations of n-alkanes ranged from 0.86 to $1.57 \mu \mathrm{g} / \mathrm{L}$. Most of the organic compounds only displayed weak seasonal variations. However, the concentrations of $\mathrm{C}_{17} \mathrm{n}$-alkanes in snow and ice samples were strongly affected by the summer monsoon.

Tuo et al. (2011) reported that fatty acids were found in all sediment samples from Erhai Lake and Gahai Lake, accompanied by lower concentrations of n-alkanes and n-alkan-2-ones. Liu et al. (2014b) investigated organic acids in the Southern Qinghai-Tibet Plateau. They speculated that secondary organic acid formation in high-elevation regions and the changes in the Asian monsoon might exert an important role in the increased organic compounds within ascending tropical moisture. Mao et al. (2015) analyzed fatty acid, amino acid, and mineral composition of four common vetch seeds on the Qinghai-Tibet Plateau. The results showed the seeds possessed low lipid (1.55-2.74\% of dry weight) and high unsaturated fatty acid (74.51-77.36\% of total fatty acid). The ratio of essential amino acid to non-essential amino acid was also high, ranging from 0.62 to 0.69 .

\subsection{Potential risks of the organic pollutants around the Qinghai-Tibet Plateau}

3.2.1. Risk assessment on fish, food, and water in the Qinghai-Tibet Plateau

The cancer risk and hazard quotient of the organic pollutants in fish, food, and water around the Qinghai-Tibet Plateau are shown in Fig. 1. OCPs were the most frequently detected in fish, food, and water samples. The detection frequencies of OCPs, PCBs, and PBDEs were $100 \%$, $58.8 \%$, and $52.9 \%$, respectively. In general, the potential risks of organic pollutants for children were 1-2 times higher than those for adults, suggesting that the children are more susceptible to the organic pollutants. The total cancer risks of organic pollutants in fish for adults ranged from $2.39 \times 10^{-6}$ to $9.01 \times 10^{-5}$, while those for children were in the range of $3.19 \times 10^{-6}-1.20 \times 10^{-4}$. Correspondingly, the total hazard quotients for adults and children were in the range of 0.0092-0.42 and $0.012-0.56$, respectively. The cancer risks/hazard quotients posed by PCBs in fish accounted for over $53.19 \% / 53.18 \%$.

Interestingly, there were scarce data of organic pollutant concentrations in water of the Qinghai-Tibet Plateau (Tables S1-S4) so that the evaluation results were only obtained from data of OCPs in water and snow. The total cancer risks and hazard quotients in water for adults/ children were $1.15 \times 10^{-5} / 2.30 \times 10^{-5}$ and $0.015 / 0.030$, respectively, mainly posed by HCHs. Accordingly, the total cancer risks and hazard quotients in snow for adults/children were $2.24 \times 10^{-8} / 4.49 \times 10^{-8}$ and $0.00011 / 0.00022$, respectively, mainly posed by DDTs. The total cancer risks of organic pollutants in food for adults ranged from $1.25 \times$ $10^{-6}$ to $2.01 \times 10^{-4}$ while those for children were in the range of $1.67 \times 10^{-6}-2.68 \times 10^{-4}$. Correspondingly, the total hazard quotients for adults and children were in the ranges of 0.0073-0.71 and 0.00970.95 , respectively.

OCPs in food posed the main potential risks. However, it was interesting that PCBs in yak milk posed the main non-carcinogenic risk (accounting for $56.7 \%$ of the total hazard quotient) while cancer risk posed by OCPs in milk reached $57.7 \%$ of the total CR, although the concentrations of PCBs in milk were 10-fold lower than those of OCPs. This suggested that PCBs possessed more serious risk than OCPs. Although the cancer risks for adults and children were ranked at low-to-moderate levels based on qualitative ranking criterion (Ge et al., 2013), the potential health risk could not be neglected, especially for the children who were more likely to be affected by the pollutants. Accordingly, the non-carcinogenic risks posed by organic pollutants also deserve more attentions since the maximal $\mathrm{HQ}(0.95)$ almost reached an unacceptable level.

\subsubsection{Risk assessment on soil/sediment in the Qinghai-Tibet Plateau}

The cancer risk and hazard quotient of the organic pollutants in soil around the Qinghai-Tibet Plateau are shown in Fig. 2. OCPs were the most frequently detected in soil/sediment. The detection frequencies of OCPs, PAHs, PCBs, and PBDEs were 65.4\%, 30.8\%, 30.8\%, and $23.1 \%$, respectively. The total CRs/HQs of organic pollutants in soil for adults were in the ranges of $\left(1.88 \times 10^{-9}-8.59 \times 10^{-6}\right) /\left(1.32 \times 10^{-5}-1.11 \times\right.$ $\left.10^{-3}\right)$ while those for children were in the ranges of $\left(2.00 \times 10^{-9}-\right.$ $\left.9.43 \times 10^{-5}\right) /\left(5.37 \times 10^{-5}-6.50 \times 10^{-3}\right)$. Accordingly, the total CRs and HQs of organic pollutants in sediment for adults were in the ranges of $1.92 \times 10^{-9}-6.99 \times 10^{-6}$ and $3.16 \times 10^{-8}-7.67 \times 10^{-5}$, respectively. For children, they were in the ranges of $2.37 \times 10^{-5}-$ $6.45 \times 10^{-4}$ and $1.46 \times 10^{-4}-2.63 \times 10^{-3}$, respectively. Based on the evaluation results, children are much more susceptible to the organic pollutants in soil/sediment than adults. The carcinogenic risks of organic pollutants in soil/sediment for children were generally 10.6-16.5 times higher than those for adults, while the non-carcinogenic risks for children were 3.9-6.2 times higher than those for adults.

The maximum HQs were much lower than 1, suggesting that noncarcinogenic risk posed by organic pollutants in soil/sediment could be very low to be neglected. However, the carcinogenic risks were ranked as very-low-to-low levels for adults and very-low-to-moderate levels for children. The results implied that the children have a higher potential to be affected by the organic pollutants in soil/sediment, and they deserved more effective protection.

PBDEs, OCPs, PCBs, and PAHs were all detected in soil/sediment. The trend in cancer risk of organic pollutants in soil/sediment was PBDEs < OCPs $<$ PCBs $<$ PAHs while the hazard quotient trend was PBDEs $<$ OCPs $<$ PAHs $<$ PCBs. These results suggested that PAHs in soil/sediment of the Qinghai-Tibet Plateau account for higher carcinogenic risks while PCBs result in higher non-carcinogenic risks. The risks posed by the organic pollutants through different routes are shown in Figs. S2-S5. In 
terms of different exposure pathways, the increasing trend in potential risks (CRs and HQs) was inhalation $<$ dermal contact $<$ ingestion, similar to that of other sites (Ge et al., 2013; Qu et al., 2015). Reducing ingestion exposure might be an effective approach to decrease potential risks of organic pollutants in soil/sediment.

\subsubsection{Risk assessment on air in the Qinghai-Tibet Plateau}

Fig. 3 shows the cancer risk and hazard quotient of the organic pollutants in air around the Qinghai-Tibet Plateau. OCPs are the most frequently detected in air, followed by PAHs and PCBs. The total CRs of organic pollutants in air for adults ranged from $6.06 \times 10^{-12}$ to $3.40 \times$ $10^{-6}$, while those for children ranged from $1.63 \times 10^{-11}$ to $9.15 \times$ $10^{-6}$. The total HQs of organic pollutants in air for adults and children ranged from $9.77 \times 10^{-8}$ to $2.77 \times 10^{-3}$. The carcinogenic risks of organic pollutants in air for children were generally 2.6-2.8 times higher than those for adults while the non-carcinogenic risks for children were as same as those for adults due to the same simplified equation and parameters. Generally speaking, children are still more affected by the pollutants in air than adults.

When OCPs, PCBs, and PAHs were all detected in air, the cancer risks and hazard quotients of organic pollutants increased in order: PCBs < OCPs $<$ PAHs. The maximum HQs were much lower than 1, suggesting that non-carcinogenic risk posed by organic pollutants in air could be very low to negligible. On the other hand, the carcinogenic risks were ranked as very-low-to-low levels for adults and children. The results implied that the organic pollutants in air still exerted potential risks to human health and ecological safety, especially with relatively high concentrations.

\section{Conclusions}

Organic pollutants widely exist in biota, water, soil, air, and food of the Qinghai-Tibet Plateau. OCPs, PAHs, PCBs, and PBDEs were most frequently detected. In general, PAHs exhibited higher concentrations in soil/sediment, air, and plants than other pollutants, while OCPs showed the highest concentrations in fish, food, and water. Based on the results of risk assessment, the cancer risks of organic pollutants in fish, food, and water for adults and children were ranked at low-to-moderate levels while the non-carcinogenic risks almost reached unacceptable levels. The carcinogenic risks of organic pollutants in soil/sediment were ranked as very-low-to-low levels for adults and very-low-tomoderate levels for children while the non-carcinogenic risks were low. Ingestion exposure was the dominant risk source. The carcinogenic risks of organic pollutants in air were ranked as very-low-to-low levels for adults and children while non-carcinogenic risk was very low to be negligible. In summary, organic pollutants in fish, food, and water exerted more serious threats to human beings and the ecological safety, whereas those in soil/sediment and air also posed potential risks and deserve attention.

\section{Acknowledgements}

This work was supported by One Hundred-Talent Plan of Chinese Academy of Sciences (Grant numbers of Y610061033 and Y629041021). The authors would like to thank the reviewers for their valuable suggestions and comments on the manuscript.

\section{Appendix A. Supplementary data}

Supplementary data to this article can be found online at http://dx. doi.org/10.1016/j.envint.2016.09.019.

\section{References}

Barro, R., Regueiro, J., Llompart, M., Garcia-Jares, C., 2009. Analysis of industrial contaminants in indoor air: part 1 . Volatile organic compounds, carbonyl compounds, polycyclic aromatic hydrocarbons and polychlorinated biphenyls. J. Chromatogr. A 1216 (3), 540-566.

Borja, J., Taleon, D.M., Auresenia, J., Gallardo, S., 2005. Polychlorinated biphenyls and their biodegradation. Process Biochem. 40, 1999-2013.

Capone, D.G., Bauer, J.E., 1992. Environmental Microbiology. Clarendon Press, Oxford.

Chen, Y., Cao, J., Zhao, J., Xu, H., Arimoto, R., Wang, G., Han, Y., Shen, Z., Li, G., 2014. n-Alkanes and polycyclic aromatic hydrocarbons in total suspended particulates from the southeastern Tibetan Plateau: concentrations, seasonal variations, and sources. Sci. Total Environ. 470-471, 9-18.

Cheng, H., Zhang, G., Jiang, J., Li, X., Liu, X., Li, J., Zhao, Y., 2007. Organochlorine pesticides, polybrominated biphenyl ethers and lead isotopes during the spring time at the Waliguan baseline observatory, northwest China: implication for long-range atmospheric transport. Atmos. Environ. 41, 4734-4747.

Cheng, H., Lin, T., Zhang, G., Liu, G., Zhang, W., Qi, S., Jones, K.C., Zhang, X., 2014. DDTs and HCHs in sediment cores from the Tibetan Plateau. Chemosphere 94, 183-189.

Daly, G.L., Wania, F., 2005. Organic contaminants in mountains. Environ. Sci. Technol. 39, 385-398.

Dietz, R., Rigét, F.F., Sonne, C., Born, E.W., Bechshøft, T., McKinney, M.A., Drimmie, R.J., Muir, D.C., Letcher, R.J., 2013. Three decades (1983-2010) of contaminant trends in East Greenland polar bears (Ursus maritimus). Part 2: brominated flame retardants. Environ. Int. 59, 494-500.

Ge, J., Woodward, L.A., Li, O.X., Wang, J., 2013. Composition, distribution and risk assessment of organochlorine pesticides in soils from the Midway Atoll, North Pacific Ocean. Sci. Total Environ. 452-453, 421-426.

Gerber, R., Smit, N.J., Van Vuren, J.H., Nakayama, S.M., Yohannes, Y.B., Ikenaka, Y., Ishizuka, M., Wepener, V., 2016. Bioaccumulation and human health risk assessment of DDT and other organochlorine pesticides in an apex aquatic predator from a premier conservation area. Sci. Total Environ. 550, 522-533.

Han, Y.M., Wei, C., Bandowe, B.A., Wilcke, W., Cao, J.J., Xu, B.O., Gao, S.P., Tie, X.X., Li, G.H., Jin, Z.D., An, Z.S., 2015. Elemental carbon and polycyclic aromatic compounds in a 150-year sediment core from Lake Qinghai, Tibetan Plateau, China: influence of regional and local sources and transport pathways. Environ. Sci. Technol. 49, 4176-4183.

He, Q., Zhang, G., Yan, Y., Zhang, Y., Chen, L., Lin, K., 2015. Effect of input pathways and altitudes on spatial distribution of polycyclic aromatic hydrocarbons in background soils, the Tibetan Plateau. Environ. Sci. Pollut. Res. 22, 10890-10901.

Huang, T., Guo, Q., Tian, H., Mao, X., Ding, Z., Zhang, G., Li, J., Ma, J., Gao, H., 2014. Assessing spatial distribution, sources, and human health risk of organochlorine pesticide residues in the soils of arid and semiarid areas of northwest China. Environ. Sci. Pollut. Res. 21, 6124-6135.

Jia, S., Wang, Q., Li, L., Fang, X., Shi, Y., Xu, W., Hu, J., 2014. Comparative study on PCDD/F pollution in soil from the Antarctic, Arctic and Tibetan Plateau. Sci. Total Environ. 497498, 353-359.

Li, J., Zhu, T., Wang, F., Qiu, X.H., Lin, W.L., 2006. Observation of organochlorine pesticides in the air of the Mt. Everest region. Ecotoxicol. Environ. Saf. 63, 33-41.

Li, C., Kang, S., Chen, P., Zhang, Q., Fang, G.C., 2012. Characterizations of particle-bound trace metals and polycyclic aromatic hydrocarbons (PAHs) within Tibetan tents of south Tibetan Plateau, China. Environ. Sci. Pollut. Res. 19, 1620-1628.

Li, L., Wang, Q., Qiu, X., Dong, Y., Jia, S., Hu, J., 2014. Field determination and QSPR prediction of equilibrium-statussoil/vegetation partition coefficient of PCDD/Fs. J. Hazard. Mater. 276, 278-286.

Liu, H., Qi, S., Yang, D., Hu, Y., Li, F., Liu, J., Xing, X., 2013a. Soil concentrations and soil-air exchange of organochlorine pesticides along the Aba profile, east of the Tibetan Plateau, western China. Front. Earth Sci. 7 (4), 395-405.

Liu, J., Li, J., Lin, T., Liu, D., Xu, Y., Chaemfa, C., Qi, S., Liu, F., Zhang, G., 2013b. Diurnal and nocturnal variations of PAHs in the Lhasa atmosphere, Tibetan Plateau: implication for local sources and the impact of atmospheric degradation processing. Atmos. Res. 124, 34-43.

Liu, X., Li, J., Zheng, Q., Bing, H., Zhang, R., Wang, Y., Luo, C., Liu, X., Wu, Y., Pan, S., Zhang, G., 2014a. Forest filter effect versus cold trapping effect on the altitudinal distribution of PCBs: a case study of Mt. Gongga, Eastern Tibetan Plateau. Environ. Sci. Technol. 48, 14377-14385.

Liu, B., Kang, S., Sun, J., Wan, X., Wang, Y., Gao, S., Cong, Z., 2014b. Low-molecular-weight organic acids in the Tibetan Plateau: results from one-year of precipitation samples at the SET station. Atmos. Environ. 86, 68-73.

Liu, H., Hu, Y., Qi, S., Xing, X., Zhang, Y., Yang, D., Qu, C., 2015. Organochlorine pesticide residues in surface water from Sichuan Basin to Aba Prefecture profile, east of the Tibetan Plateau. Front. Earth Sci. 9, 248-258.

Mao, Z., Fu, H., Nan, Z., Wan, C., 2015. Fatty acid, amino acid, and mineral composition of four common vetch seeds on Qinghai-Tibetan plateau. Food Chem. 171, 13-18.

Meironyté, D., Norén, K., Bergman, Å., 1999. Analysis of polybrominated diphenyl ethers in Swedish human milk. A time-related trend study, 1972-1997. J. Toxicol. Environ. Health A 58, 101-113.

Mrema, E.J., Rubino, F.M., Brambilla, G., Moretto, A., Tsatsakis, A.M., Colosio, C., 2013. Persistent organochlorinated pesticides and mechanisms of their toxicity. Toxicology 307, 74-88.

Ni, K., Lu, Y., Wang, T., Kannan, K., Gosens, J., Xu, L., Li, Q., Wang, L., Liu, S., 2013. A review of human exposure to polybrominated diphenyl ethers (PBDEs) in China. Int. J. Hyg. Environ. Health 216, 607-623.

Pan, J., Gai, N., Tang, H., Chen, S., Chen, D., Lu, G., Yang, Y., 2014. Organochlorine pesticides and polychlorinated biphenyls in grass, yak muscle, liver, and milk in Ruoergai high altitude prairie, the eastern edge of Qinghai-Tibet Plateau. Sci. Total Environ. 491492, 131-137.

Pandey, S.K., Kim, K.-H., Brown, R.J.C., 2011. A review of techniques for the determination of polycyclic aromatic hydrocarbons in air. TrAC, Trends Anal. Chem. 30 (11), 1716-1739. 
Purcaro, G., Moret, S., Conte, L.S., 2013. Overview on polycyclic aromatic hydrocarbons: occurrence, legislation and innovative determination in foods. Talanta 105, 292-305.

Qu, C., Qi, S., Yang, D., Huang, H., Zhang, J., Chen, W., Yohannes, H.K., Sandy, E.H., Yang, J., Xing, X., 2015. Risk assessment and influence factors of organochlorine pesticides (OCPs) in agricultural soils of the hill region: a case study from Ningde, southeast China. J. Geochem. Explor. 149, 43-51.

Ravindra, K., Sokhi, R., Grieken, R.V., 2008. Atmospheric polycyclic aromatic hydrocarbons: source attribution, emission factors and regulation. Atmos. Environ. 42, 2895-2921.

Ren, J., Wang, X., Xue, Y., Gong, P., Joswiak, D.R., Xu, B., Yao, T., 2014. Persistent organic pollutants in mountain air of the southeastern Tibetan Plateau: seasonal variations and implications for regional cycling. Environ. Pollut. 194, 210-216.

Rovira, J., Mari, M., Nadal, M., Schuhmacher, M., Domingo, J.L., 2010. Environmental monitoring of metals, PCDD/Fs and PCBs as a complementary tool of biological surveillance to assess human health risks. Chemosphere 80, 1183-1189.

Shi, Y., Pan, Y., Yang, R., Wang, Y., Cai, Y., 2010. Occurrence of perfluorinated compounds in fish from Qinghai-Tibetan Plateau. Environ. Int. 36, 46-50.

Sultana, J., Syed, J.H., Mahmood, A., Ali, U., Rehman, M.Y., Malik, R.N., Li, J., Zhang, G., 2014. Investigation of organochlorine pesticides fromthe Indus Basin, Pakistan: sources, air-soil exchange fluxes and risk assessment. Sci. Total Environ. 497-498, 113-122.

Sun, Y., Yuan, G.-L., Li, J., Li, J.-C., Wang, G.-H., 2015. Polybrominated diphenyl ethers in surface soils near the Changwengluozha Glacier of Central Tibetan Plateau, China. Sci. Total Environ. 511, 399-406.

Tao, S., Wang, W., Liu, W., Zuo, Q., Wang, X., Wang, R., Wang, B., Shen, G., Yang, Y., He, J., 2011. Polycyclic aromatic hydrocarbons and organochlorine pesticides in surface soils from the Qinghai-Tibetan plateau. J. Environ. Monit. 13, 175-181.

Tao, Y.-Q., Lei, G.-L., Xue, B., Yao, S.-C., Pu, Y., Zhang, H.-C., 2014. Deposition and regional distribution of HCHs and p, p'-DDX in the western and southern Tibetan plateau: records from a lake sediment core and the surface soils. Environ. Sci. Pollut. Res. 21, 1875-1883.

Tian, Z., Li, H., Xie, H., Tang, C., Han, Y., Wang, M., Liu, W., 2014. Polychlorinated dibenzop-dioxins and dibenzofurans and polychlorinated biphenyls in surface soil from the Tibetan Plateau. J. Environ. Sci. 26, 2041-2047.

Tuo, J., Wu, C., Zhang, M., Chen, R., 2011. Distribution and carbon isotope composition of lipid biomarkers in Lake Erhai and Lake Gahai sediments on the Tibetan Plateau. J. Great Lakes Res. 37, 447-455

USDA (United States Department of Agriculture), 2015. Scientific Report of the 2015 Dietary Guidelines Advisory Committee. Advisory Report to the Secretary of Health and Human Services and the Secretary of Agriculture (available on) http://health.gov/ dietaryguidelines/2015-scientific-report/pdfs/scientific-report-of-the-2015-dietaryguidelines-advisory-committee.pdf.

USEPA (U.S. Environmental Protection Agency), 1994. Technical Background Document for Draft Soil Screening Level Guidance. (Available on) http://nepis.epa.gov/Exe/ ZyPURL.cgi?Dockey=2000A6PR.txt.

USEPA (U.S. Environmental Protection Agency), 1996. PCBs: A Cancer Dose-Response Assessment and Applications to Environmental Mixtures, EPA/600/P-96/001F.

USEPA (U.S. Environmental Protection Agency), 2016. Regional Screening Levels (RSLs) User's Guide. (available on) https://www.epa.gov/risk/regional-screening-levelsrsls-users-guide-may-2016.

Wang, X., Yao, T., Cong, Z., Yan, X., Kang, S., Zhang, Y., 2006. Gradient distribution of persistent organic contaminants along northern slope of central-Himalayas, China. Sci. Total Environ. 372, 193-202.

Wang, X.P., Yao, T.D., Cong, Z.Y., Yan, X.L., Kang, S.C., Zhang, Y., 2007a. Distribution of persistent organic pollutants in soil and grasses around Mt. Qomolangma, China. Arch. Environ. Contam. Toxicol. 52, 153-162.

Wang, X.P., Yao, T.D., Cong, Z.Y., Yan, X.L., Kang, S.C., Zhang, Y., 2007b. Concentration level and distribution of polycyclic aromatic hydrocarbons in soil and grass around Mt. Qomolangma, China. Chin. Sci. Bull. 52, 1405-1413.

Wang, F., Zhu, T., Xu, B.Q., Kang, S.C., 2007c. Organochlorine pesticides in freshfallen snow on East Rongbuk Glacier of Mt. Qomolangma (Everest). Sci. China Ser. D Earth Sci. 50, 1097-1102.

Wang, P., Zhang, Q., Wang, Y., Wang, T., Li, X., Li, Y., Ding, L., Jiang, G., 2009. Altitude dependence of polychlorinated biphenyls (PCBs) and polybrominated diphenyl ethers (PBDEs) in surface soil from Tibetan Plateau, China. Chemosphere 76, 1498-1504.

Wang, X., Dong, P., Yao, T., Jones, K.C., 2010a. Passive air sampling of organochlorine pesticides, polychlorinated biphenyls, and polybrominated diphenyl ethers across the Tibetan Plateau. Environ. Sci. Technol. 44, 2988-2993.
Wang, Y., Yang, R., Wang, T., Zhang, Q., Li, Y., Jiang, G., 2010b. Assessment of polychlorinated biphenyls and polybrominated diphenyl ethers in Tibetan butter. Chemosphere 78, 772-777.

Wang, X., Sheng, J., Gong, P., Xue, Y., Yao, T., Jones, K.C., 2012. Persistent organic pollutants in the Tibetan surface soil: spatial distribution, air-soil exchange and implications for global cycling. Environ. Pollut. 170, 145-151.

Wang, X., Xue, Y., Gong, P., Yao, T., 2014a. Organochlorine pesticides and polychlorinated biphenyls in Tibetan forest soil: profile distribution and processes. Environ. Sci. Pollut. Res. 21, 1897-1904.

Wang, C., Wang, X., Gong, P., Yao, T., 2014b. Polycyclic aromatic hydrocarbons in surface soil across the Tibetan Plateau: spatial distribution, source and air-soil exchange. Environ. Pollut. 184, 138-144.

Wang, X., Halsall, C., Codling, G., Xie, Z., Xu, B., Zhao, Z., Xue, Y., Ebinghaus, R., Jones, K.C. 2014c. Accumulation of perfluoroalkyl compounds in Tibetan Mountain snow: temporal patterns from 1980 to 2010. Environ. Sci. Technol. 48, 173-181.

Wang, X., Gong, P., Sheng, J., Joswiak, D.R., Yao, T., 2015. Long-range atmospheric transport of particulate polycyclic aromatic hydrocarbons and the incursion of aerosols to the southeast Tibetan Plateau. Atmos. Environ. 115, 124-131.

Wang, C., Wang, X., Gong, P., Yao, T., 2016. Residues, spatial distribution and risk assessment of DDTs and HCHs in agricultural soil and crops from the Tibetan Plateau. Chemosphere 149, 358-365.

Xiao, H., Kang, S.C., Zhang, Q.G., Han, W.W., Loewen, M., Wong, F., Hung, H., Lei, Y.D. Wania, F., 2010. Transport of semivolatile organic compounds to the Tibetan Plateau: monthly resolved air concentrations at Nam Co. J. Geophys. Res. 115, D16310.

Xie, S., Yao, T., Kang, S., Xu, B., Duan, K., Thompson, L.G., 2010. Geochemical analyses of a Himalayan snowpit profile: implications for atmospheric pollution and climate. Org. Geochem. 31, 15-23.

Xing, X.-L., Qi, S.-H., Zhang, Y., Yang, D., Odhiambo, J.O., 2010. Organochlorine pesticides (OCPs) in soils along the Eastern slope of the Tibetan Plateau. Pedosphere 20 (5), 607-615.

Yang, R., Yao, T., Xu, B., Jiang, G., Xin, X., 2007. Accumulation features of organochlorine pesticides and heavy metals in fish from high mountain lakes and Lhasa River in the Tibetan Plateau. Environ. Int. 33, 151-156.

Yang, R., Wang, Y., Li, A., Zhang, Q., Jing, C., Wang, T., Wang, P., Li, Y., Jiang, G., 2010. Organochlorine pesticides and PCBs in fish from lakes of the Tibetan Plateau and the implications. Environ. Pollut. 158, 2310-2316.

Yang, R., Jing, C., Zhang, Q., Wang, Z., Wang, Y., Li, Y., Jiang, G., 2011. Polybrominated diphenyl ethers (PBDEs) and mercury in fish from lakes of the Tibetan Plateau. Chemosphere 83, 862-867.

Yang, R., Zhang, S., Li, A., Jiang, G., Jing, C., 2013. Altitudinal and spatial signature of persistent organic pollutants in soil, lichen, conifer needles, and bark of the Southeast Tibetan Plateau: implications for sources and environmental cycling. Environ. Sci. Technol. 47, 12736-12743.

Yuan, G.-L., Han, P., Xie, W., Che, X.-C., Wang, G.-H., 2012a. Altitudinal distribution of polybrominated diphenyl ethers (PBDEs) in the soil along Central Tibetan Plateau, China. Sci. Total Environ. 433, 44-49.

Yuan, G.-L., Xie, W., Che, X.-C., Han, P., Liu, C., Wang, G.-H., 2012b. The fractional pattern of polybrominated diphenyl ethers in the soil of the central Tibetan Plateau, China: the influence of soil components. Environ. Pollut. 170, 183-189.

Yuan, G.-L., Qin, J.-X., Li, J., Lang, X.-X., Wang, G.-H., 2014. Persistent organic pollutants in soil near the Changwengluozha glacier of the Central Tibetan Plateau, China: their sorption to clays and implication. Sci. Total Environ. 472, 309-315.

Yuan, G.-L., Sun, Y., Li, J., Han, P., Wang, G.-H., 2015a. Polychlorinated biphenyls in surface soils of the Central Tibetan Plateau: altitudinal and chiral signatures. Environ. Pollut 196, 134-140.

Yuan, G.-L., Wu, L.-J., Sun, Y., Li, J., Li, J.-C., Wang, G.-H., 2015b. Polycyclic aromatic hydrocarbons in soils of the central Tibetan Plateau, China: distribution, sources, transport and contribution in global cycling. Environ. Pollut. 203, 137-144.

Zheng, X., Liu, X., Jiang, G., Wang, Y., Zhang, Q., Cai, Y., Cong, Z., 2012. Distribution of PCBs and PBDEs in soils along the altitudinal gradients of Balang Mountain, the east edge of the Tibetan Plateau. Environ. Pollut. 161, 101-106.

Zhu, N., Schramm, K.W., Wang, T., Henkelmann, B., Zheng, X., Fu, J., Gao, Y., Wang, Y., Jiang, G., 2014. Environmental fate and behavior of persistent organic pollutants in Shergyla Mountain, southeast of the Tibetan Plateau of China. Environ. Pollut. 191, 166-174.

Zhu, N., Schramm, K.W., Wang, T., Henkelmann, B., Fu, J., Gao, Y., Wang, Y., Jiang, G., 2015 Lichen, moss and soil in resolving the occurrence of semi-volatile organic compounds on the southeastern Tibetan Plateau, China. Sci. Total Environ. 518-519, 328-336. 